Research Article

\title{
Investigating the Effective Factors of Renewable Energy Development in Tehran Metropolis
}

\author{
Mohammad Reza Arasteh Taleshmekaiil $\mathbb{D}^{1},{ }^{1}$ Seyed Mohammad Reza Khatibi $\mathbb{D}^{1,2}$ \\ Mona Mohemsaz $\left(\mathbb{0},{ }^{3}\right.$ Mohammad Hossein Azimi, ${ }^{2}$ and Ali Sadeghpour ${ }^{4}$ \\ ${ }^{1}$ Faculty of Urbanism Engineering, Islamic Azad University of North Tehran, Tehran, Iran \\ ${ }^{2}$ Department of Urbanism, Faculty of Architecture and Urbanism Engineering, Qazvin Branch, Islamic Azad University, \\ Qazvin, Iran \\ ${ }^{3}$ Faculty of Urban and Regional Planning, Science and Research Branch, Islamic Azad University, Tehran, Iran \\ ${ }^{4}$ Faculty of Engineering, Varamin-Pishva Branch, Islamic Azad University, Tehran, Tehran Province, Iran \\ Correspondence should be addressed to Seyed Mohammad Reza Khatibi; m_khatibi@qiau.ac.ir
}

Received 26 December 2020; Revised 7 February 2021; Accepted 18 February 2021; Published 8 March 2021

Academic Editor: Noorbakhsh Amiri Golilarz

Copyright (C) 2021 Mohammad Reza Arasteh Taleshmekaiil et al. This is an open access article distributed under the Creative Commons Attribution License, which permits unrestricted use, distribution, and reproduction in any medium, provided the original work is properly cited.

\begin{abstract}
To prepare for the urban development of 2.5 billion people by 2050, the development of low-carbon, resilient, and liveable urban settlements is crucial. Not only do metropolises contribute to global climate change by rapidly emitting and increasing emissions but they themselves are very fragile and vulnerable to these changes. The purpose of this study is to optimize a model for the development of renewable energies in Tehran City and its application in different sectors to achieve sustainability. The research method is according to the type of the applied-developmental study. Information is based on documentation and field methods. Data were collected using a questionnaire from 76 experts and analysed using MICMAC software. The results indicate the fact that the use of public and specific stimuli and incentives for electricity producers to use renewable energy will accelerate the development of renewable energy at the urban level. In order to improve the existing situation, the unsustainable model can be offered to change the situation in favour of the use of new energy at the regional level. Based on the research results, in general, patterns of deployment and development of renewable energies are grouped into five main groups: the use of financial instruments, the use of legal instruments, the development of technology, education and awareness-raising that urban sustainability in the energy sector can be considered based on these four pillars.
\end{abstract}

\section{Introduction}

The path taken today to use modern energy to achieve sustainable development goals can be seen as a scientific challenge for its realization in the modern age [1]. With their ever-expanding development, today's cities are large parts of Iran's metropolises' energy consumption and not exemplary. A metropolis like Tehran, accounting for only less than $12 \%$ of the country, accounts for 15\% of its air pollution level [2]. Paying attention to new approaches in the field of energy can be a viable solution to many urban biodiversity problems in the future. There are many related areas and technologies that can be used for this aim, such as sensor fusion systems
[3], intelligent damage detection [4-6], monitoring systems [7-10], parameters optimization [11], optimization [12], smart grid [13], computer vision systems [14], power allocation systems [15], image and video processing [16-21], and decision-making approaches [22-24].

According to the Tehran Electricity Distribution Company, Tehran city consumes about $20 \%$ of the country's total electricity. These statistics show that the need to pay attention to other energy production aspects can be an inevitable necessity. Tehran has serious problems with the supply and distribution of pollution in the energy production and consumption sector. Meanwhile, renewable energy as a sustainable solution in the field of energy 
production and pollution of urban air in recent years has received much attention. Renewable energies are energies with a sustainable production process and continuous replacement capability, which according to this definition, the process of sustainable production is the use of natural or artificial cycles that can continuously convert raw materials into the desired energy and if there is any an operation or need for storage, can be capable of continuous replacement [25].

Urban development can be considered as a multidimensional concept that includes economic, social, and environmental approaches. Management problems in this process always exist between the urban space, stakeholders, and urban infrastructure. This complexity requires multidimensional approaches and specific quantitative or qualitative methods to analyse and synthesize various aspects of transformation processes, from environmental impacts on urban renewal to energy impacts, economic development, and development strategies. Sustainable energy systems are always in complex communication with the community and the development of technical infrastructure. The successful development of a sustainable energy system depends on social acceptance, market dynamics, regulations and policies, and different producer groups' support. Natural energy sources such as solar energy are increasing due to the high potential of exploitation and use as sources of heating, air conditioning, and electricity and can be reduced by developing fossil fuel consumption. As a major source of sustainable energy, benefits bring a lot to the community [26-28].

Energy production and consumption have some considerations, which directly affect the sustainability of the urban environment. In fact, the depletion of fossil fuels and greenhouse gas emissions due to the oil and coal-based model or the occupation of natural spaces for centralized reproduction models should be considered. Rather, energy production costs are also increasing. These costs affect the income statement, in economic activities, which may include variable value regarding the total cost of energy production, between 5 and 40 percent of total costs that are more in terms of cost of energy production and service delivery [29-32].

Generally, energy efficiency is defined as the relationship between production, services, and energy costs [33]. Therefore, through energy efficiency, energy saving by maintaining the same energy consumption as expected without reduction, production and comfort levels, guaranteed supply, sustainability, and environmental protection are also available as desirable targets. This sustainability process involves saving various energy sources used, such as oil, coal, and natural gas $[34,35]$.

Developing the application of renewable energy technologies is becoming a strategic option given the reduction of greenhouse gases as a global energy source. During the last two decades, the use of new energies has been considered in two parts. The first is related to the direct production of heat, and the second is related to the production of electricity [36]. According to the UN Environment Program in 2016, households consume about $40 \%$ of the world's energy. This volume of energy consumption in Iran is mainly from the consumption of seasonal resources that emit a large volume of greenhouse gases, which in large cities such as Tehran in Iran causes a lot of air pollution. Iran is one of the top 10 countries in carbon dioxide $\left(\mathrm{CO}_{2}\right)$ emissions, with rapid urbanization and migration. Industrial growth and sociopolitical developments are the main factors in the rapid growth of cities [37, 38].

The study on the energy consumption of urban households and $\mathrm{CO}_{2}$ emissions in a country like Iran with a population of more than 80 million people and a neutralization rate of $3.5 \%$ is important [39]. Fossil fuel groups (coal, oil, and natural gas) are used worldwide as the main energy source, which also comprises a very high percentage of primary energy that includes the areas of scarcity and rising prices in this segment of resources. Therefore, it can be said that the current power system has problems on its own, which has uncontrollable environmental consequences and numerous negative environmental consequences (climate change, greenhouse effect, acid rain, and deforestation) and geopolitical instability $[40,41]$. That change in this traditional system due to the existing problems such as cities' physical development, population growth, industrial development, and biological pollution can provide planners with a sustainable solution through the use of new energies.

Although fossil fuels are still a major source of energy in cities, the use of renewable energy as a fundamental solution to metropolitan areas' problems is becoming increasingly urgent [30]. Many renewable energy technologies, such as photovoltaic panels, small wind turbines, micro turbines, and gas engines, are increasingly being integrated into power distribution systems [42] and can be used in urban areas.

Extensive use of renewable energy is a new approach in urban planning in order to achieve sustainable urban development. The development of low-carbon cities is one of the most important executive approaches in this field. Depending on the resources available in each geographical area, the type of use of renewable energy is different and requires its own scenarios.

In a study by Child et al., two transition pathways towards a $100 \%$ renewable energy (RE) power sector by 2050 are simulated for Europe using the LUT energy system transition model. The first is a region scenario, whereby regions are modelled independently, and the second is an area scenario, which has transmission interconnections between regions [6].

Future technologies such as homogeneous systems and biomass heating in cities are characterized by energy saving and high energy efficiency. Developmental research on renewable energy models in urban areas has become a necessity for achieving a sustainable energy system. Many cities around the world have expressed their commitment to $100 \%$ energy use from these clean sources, and it is predicted that by 2025 , cities like Copenhagen and Munich will be able to source electricity from renewable sources. As such, these cities can be considered as zero-carbon cities. According to the Tehran city council resolution, Tehran's municipality is obliged to change the use of electricity to $20 \%$ by using public energy. During this time, Tehran's waste incinerator 
has been set up to generate $3 \mathrm{MWh}$ (Megawatt hour) of electricity. In addition to equipping many of Tehran's public spaces with solar panels, Tehran's municipality has implemented extensive policies to provide $20 \%$ of the city's public electricity with renewable energy. Today, the use of green energy in urban areas reflects areas where the scientific community of large-scale urban renewable energy production is interested as a solution for sustainable energy development. Because it can be considered sustainable solutions to meet the growing demand for energy in cities and to reduce greenhouse gas emissions as an important principle of sustainability in energy issues, research is essential to achieving energy efficiency and profitability in sustainable renewables over time, and its use in urban areas can be considered one of the most important energies and urbanization challenges of today [42-49].

Today, the use of renewable energy in urban areas is a field that is considered by urban planners. Extensive use of renewable energy in urban areas on a large scale is assumed to be a solution for sustainable energy development, both to meet the growing energy needs of cities and to reduce carbon emissions. To access these efficient, profitable, and sustainable energy sources, it is necessary to increase the technical capabilities, investment, public awareness, and responsibilities of governments. Then, by considering an ideal condition for the development of these energies in urban areas, a model for its development can be presented.

The present study explores the potential for utilization and coverage of various renewable energy sources and the practical implementation of related technologies for the security of sustainable development in the Tehran metropolis. Many city-states face many problems in their metropolises, but commonalities can be found in the development of renewable energy. Research and development funds are allocated for the application of these energies in cities. However, this is not common and is not supported in many countries, which in turn slows down innovation in this area. In Iran, especially in metropolises such as Tehran, subsidies and incentive policies are often in conflict with each other. Contrary to conventional global policies, policies aimed at promoting renewable energy technologies in Iran are constantly changing, and despite the tendency to take this approach, the policies run counter to the public interest and discourage acceptance. When the incentives to use this type of energy in society are eliminated, private companies that provide services and develop the technical sector will also go bankrupt. Also, the ever-changing subsidies and legal barriers to employment are increasingly making it difficult to access renewable energy projects. In Tehran, excessive air pollution, greenhouse gas emissions, high energy consumption, and a high potential for renewable energy have always been an incentive to develop this type of energy. But so far, this has not happened due to the problems mentioned. Recognizing the challenges of this creature and providing appropriate solutions can overcome these obstacles.

\section{Research Method}

This study seeks to identify the factors affecting the utilization of new energy at urban levels, emphasizing Tehran's District 4 . The research method is applied-developmental. This research tries to determine the potential of applying the new energy and presenting the most optimal strategies in the Tehran 4 area. Accordingly, the research data gathering tool, conducted in 1977, is based on documentary and field methods. To select the main and measurable variables for problem analysis, books, theses, and related articles were studied. Moreover, after identifying different metrics for utilizing and evaluating the potential of new energies, following the comments of professors and experts in the field, three main dimensions (solar, wind, and geothermal) were selected in the areas of applicability and productivity, which are analysed based on the MICMAC analytical method in statistical analysis. The research's statistical population is specialists and experts in the field of development and utilization of new energies. The selected sample is 76 people, that the questionnaire was developed to investigate the interrelationships of each of the indicators in relation to each other as a matrix and distributed among them. The target population is Ph.D. graduates in civil engineering, urban planning, energy economics, geography, and urban planning and experts with at least 8 years' experience in the field of modern energy development in Tehran municipality New Energy Organization of Tehran. Of the statistical sample, 76 have indicated their readiness to participate in this study. The sample survey comments were present at all stages of the research, and that is why the type of sampling is considered integer. The descriptive characteristics of the statistical sample in question are given in Table 1.

2.1. Study Area. Tehran Region 4 is located on the southern slope of Alborz Range and northeast of Tehran Metropolis and is the largest and most populous area among the 22 districts of Tehran. This area covers an area of 6123.9 hectares with a population of 917261 (in 2015). According to these figures, this specific area covers $7.2 \%$ of the total area and $10.5 \%$ of the population of Tehran metropolis. Tehran District 4 has 9 districts and 20 neighbourhoods, and after District 22, it has the largest privacy limit. This area is bounded on the north by Area 1 and on the west by Anchor Street at Area 1 and in the Pasdaran by Area 3, on the south by the Resalat Street border at Districts 7 and 8, and near Damavand St. by District 13, on the south. Thus, District 4 has zones 1, 3, 7, 8, and 13 in common and adjacent bodies (http://www.amar. org.ir). In terms of land use in Region 4, $11.1 \%$ and $10.5 \%$, respectively, of the city's textured area and $18 \%$ of the open and green areas and its expandable lands are much more than other areas of Tehran, respectively. The existence of Sorkheh Hesar, Lawizan, and Lashkara Parks has added to the attractiveness of the area and its contribution to regional performance levels. The presence of East Tehran's industrial 
TABle 1: Descriptive characteristics of the statistical sample of the research.

\begin{tabular}{lc}
\hline Field of study/organ & Number \\
\hline PhD of Civil & 7 \\
PhD of Urban Planning & 21 \\
PhD of Energy Economics & 14 \\
PhD of Geography and Urban Planning & 13 \\
Municipality experts & 11 \\
New energy organization experts & 10 \\
\hline
\end{tabular}

district has increased the possibilities for job creation, production, and added to the trans-regional physical mobility [50].

\subsection{Data Analysis}

2.2.1. The Pattern of Deployment of New Energy for Sustainable Development in the District 4 of Tehran. Looking at the future and its alternatives is very difficult for humankind to live in a society of constant change. Scriptwriting is perhaps the most crucial foresight methodology that can model the probable futures that are structured to reflect different organizations and systems' futures. Because of its efficiency in time uncertainty and complexity, this technique is a valuable tool that helps organizations prepare for possible futures, and it makes organizations more flexible and innovative.

In this research, after identifying the issue, the key factors and drivers related to modern energy application in the $4^{\text {th }}$ district of Tehran 41 (with 76 experts of urban affairs and modern energy development) were investigated. Then, the key factors and driving forces were rated based on the degree of significance and uncertainty; the rating scale $(0=$ trivial, $1=$ weak, $2=$ moderate, $3=$ strong, $P=$ potential impact) was used to determine the significance of the responses. At the beginning of the discussion, we consider the title given that there are a large number of cases (41 cases) in the process of running the software and each one with a code which are illustrated in Table 2. Each of these factors is assigned codes from 1 to 41 . The $41^{*} 41$ matrix was formed and analysed in the MICMAC software based on the mean scores given to the propellants. Of the 1681 relationships evaluated in this matrix, 771 were zero. 549 number one relationships, 291 two relationships, and 51 three and $19 \mathrm{P}$ relationships had a potential impact. Matrices based on a statistical index with data rotation twice were $100 \%$ desirable and optimized, which indicates the high validity of the questionnaire and its answers (Tables 3 and 4).

At the end of every matrix, the quantity of repetition must be aligned towards a certain limit. Based on the number of adjustments, the correct classification of criteria is formed. Finally, with the impact and dependence of these criteria, the MDI matrix is obtained.

\section{Direct Indicator (MDI) and Indirect Impact Matrix (MII)}

Indirect impact matrix (MII) is consistent with direct impact matrix (MDI), which increases with the power of repetition by continuous repetitions. From this matrix, the new classification of variables emphasizes the most important variables of the system. In fact, because of the matrix multiplication program applied to indirect classification, it detects a hidden variable. This program examines the effects of feedback by methods and loops of feedback and thus based on a hierarchical set of variables. In the order of influence, given the number of paths and loops of length $1,2, \ldots, N$ created by any variable; given the number of paths and loops of length 1 , $2, \ldots, N$ in each variable, respectively, dependence. In general, the classification is multiplied by 3,4 , or 5 .

3.1. Direct Impact Matrix (MDI Matrix). As previously mentioned, 41 driving factors, each identified in the software as a code, form the study's basis. According to the cases mentioned earlier, each index's status can be distinguished by the position of the distribution of the indexes and their position in the influence-matrix of the direct effects matrix. Thus, the indicators' distribution map shows that eleven indicators (code 1, 10, 13, 15, 21, 24, 28, 30, 31, 37, and 38) are the impacts of the indicators on the system. Indicators in this area of the chart have the most impact and the least impact, and as the most critical indicators, the status of the system and its changes depend on them. The identified indicators are system inputs, and the system cannot control them because they are out of the system and act as stable indicators.

3.1.1. Bidirectional Indicators. Seven indicators (code 3, 4, 5, $11,19,32$, and 41) are identifiable as bidirectional indicators in the system. It means that, at the same time, they are influential and effective, and their nature is unstable. So, every action and change on them will cause a reaction and change on another.

3.1.2. Risk Indicators. Risk indicators are indexes (code 4, 5, 11 , and 32); that is, they have a very high capacity to become key players in the system, and because of their unstable nature, they have the potential to become a breakpoint of the system (application of new energy at the urban level).

3.1.3. Target Indicators. Code 3, 19, and 41 are introduced as target indicators. These indicators are more than influential and can be identified with acceptable certainty due to system evolution. The system changes and evolves in the desired direction. Therefore, these indicators represent the targets set in the system rather than displaying a predetermined result. 
Table 2: Propulsion forces identified from the interviews and sources studied.

\begin{tabular}{|c|c|}
\hline Code & Propulsion forces \\
\hline 1 & The upward trend in the price of fossil energy \\
\hline 2 & Power generation during peak hours \\
\hline 3 & Reduce greenhouse gas emissions by using new energy \\
\hline 4 & Competitiveness of renewable energy generation \\
\hline 5 & Reliable investment in renewable energy due to the reliability of electricity generation from these sources \\
\hline 6 & Providing clean power for specific applications with high area and consumption \\
\hline 7 & Unlimited increase in energy consumption \\
\hline 8 & The high cost of energy production in traditional ways \\
\hline 9 & Dependence of renewable energies on geographical and environmental conditions at the regional level \\
\hline 10 & Manufacturing technology of domestic types of equipment \\
\hline 11 & Obtaining energy resources at a lower cost and higher productivity \\
\hline 12 & Balance and justice accessible to energy at affordable prices \\
\hline 13 & Liberalization and privatization of the energy sector \\
\hline 14 & Increasing energy conversion efficiency and productivity \\
\hline 15 & Change in the consumption process \\
\hline 16 & Ensuring the security of energy supply, establishing competition, and protecting the environment \\
\hline 17 & Continued optimization of energy supply and demand \\
\hline 18 & Reforming the energy pricing system \\
\hline 19 & Development of the use of renewable energies \\
\hline 20 & Developing specific environmental standards for the clean energy industry \\
\hline 21 & Energy sector restructuring \\
\hline 22 & Action to economize technology in the use of new energy \\
\hline 23 & Developing policies for the uptake, transfer of new technologies such as renewable technologies \\
\hline 24 & Preparing energy consumption standards and guidelines for energy consumption by different sectors \\
\hline 25 & Formulate and implement policies necessary to establish energy consumption standards \\
\hline 26 & Energy consumption audit and monitoring \\
\hline 27 & Preparation of energy management law and supervision of good enforcement of energy laws \\
\hline 28 & Modification of existing technologies \\
\hline 29 & Education, awareness, and information \\
\hline 30 & Providing government facilities \\
\hline 31 & Provision of technical facilities by the municipality and the organization of new energy \\
\hline 32 & Development of new energy infrastructure at the regional level \\
\hline 33 & Maximum efficiency of modern energy efficiency \\
\hline 34 & Provision of legal facilities by the municipality for the development and use of modern energy \\
\hline 35 & Cultivation and training in the use and importance of new energies \\
\hline 36 & Public propaganda on the use of new energies \\
\hline 37 & Having the knowledge of applying \\
\hline 38 & Cooperation of various institutions in facilitating the use of modern energy in the private sector \\
\hline 39 & Providing consulting services from the municipality and the organization of new energy \\
\hline 40 & Creating employment in the field of modern energies \\
\hline 41 & Development and application of clean transport \\
\hline
\end{tabular}

TABLE 3: Initial analysis of interaction matrix data.

\begin{tabular}{lc}
\hline Indicator & Value \\
\hline Matrix size & 41 \\
Number of iterations & 2 \\
Number of zeros & 771 \\
Number of ones & 549 \\
Number of twos & 291 \\
Number of threes & 51 \\
Number of P & 19 \\
Total & 910 \\
Fill rate & $54 / 13445 \%$
\end{tabular}

Source: MICMAC software output, analysis of author's findings.

TABLE 4: Matrix utility and optimization.

\begin{tabular}{lcc}
\hline Iteration & Influence (\%) & Dependence (\%) \\
\hline 1 & 99 & 95 \\
2 & 100 & 101 \\
\hline
\end{tabular}


3.1.4. Influential or Affiliate Indicators. Influential or affiliate indicators (codes 6 and 33), with low impact and high effectiveness, are system-dependent indicators that are very sensitive to the evolution of two-way variables. These indicators can be considered as system output.

3.1.5. Independent and Exempt Indicators. Independent and exempt indicators (codes 2, 7, 8, 9, 12, 16, 18, 23, 25, 26, 27, $29,34,35,36,37,40)$ are identified as independent system indicators. That means, these indicators are not significantly affected by other system indicators, and they have little or no effect on them. These indicators have very little to do with the system. Thus, they do not stop the main indicator nor evolve a variable in the system.

3.1.6. Among These Indicators. Discrete indicators: the position of the power generation index at peak hours (code 2) indicates that it has nothing to do with the dynamics and current changes of the system in terms of applying new energy to sustain the region, and they can be logged out of the system.

3.1.7. Leverage and Secondary Indicators. The leverage and secondary indicators (codes, 8, 9, 12, 14, 16, 7, 18, 23, 26, 27, $29,34,35,36,39,40)$ are more than influential since they have a strong influence on the system and have leverage in its dynamics, and they can be of particular interest as a starting point to start.

3.1.8. Regulatory Indicators. Regulatory indicators (codes 20, 17 , and 22) in area 4 of the diagram can act as secondary leverage, weak targets, or secondary biomarkers. Finally, Figure 1 shows a graphical representation of the indicators studied concerning the pattern of renewable energy use in Tehran's District 4 area. In this figure, the direct effects of the indicators on other indicators of the system are specified. How indicators affect the weakest effects, weak effects, intermediate effects, strong effects, and potential effects is visible.

3.2. Indirect Impact Matrix (MII Matrix). By the application, indirect effects of each index have been raised to the powers of $2,3,4,5$, and so on. As a result, the indirect effects of each index were calculated using the renewable energy models. It has been measured at level 4 of Tehran city. The indicators' indirect interaction matrices (codes 3, 4, 10, 19, 28, and 32) have more influence and impact than other variables. The results show the high impact of these six indicators on the system. These indicators can have a greater impact on the use of new energy and make it one of the most influential indicators. The distribution of indexes and their position on the damage axis, the indirect effects of the Matrix on the condition of each index, with their position on the axis, are as follows.

3.2.1. Influential Indicators. The map of the index distribution indicates that the matrix of indirect effects with the codes of $1,10,13,20,24,28,30,31$, and 38 is the most effective indices.

3.2.2. Bidirectional Indicators. Nine indicators (codes $3,4,5$, 19) are identifiable as bidirectional indicators in the system. It means that they are very effective at the same time, and their nature is mixed with instability. So, every action and change on them will cause a reaction and change on another.

3.2.3. Risk Indicators. The energy resource utilization indicator with lower cost and higher productivity (code 11) is known as the only risk indicator in the system; that is, they have a very high capacity to become key players in the system, and because of their unstable nature, they have the potential to become a breakpoint of the system (the application of new energy at the municipal level).

3.2.4. Target Indicators. Codes 32 and 41 are introduced as target indicators. This means that in this matrix no indicator can be identified with certainty as a result of the evolution of the system to achieve the desired pattern changes and evolution.

3.2.5. Affective or Dependent Indicators. As with the direct effects matrix, the matrices (codes 14, 33, and 40) have lowimpact and high-impact indicators, which are very sensitive to the evolution of two-way variables. These indicators can be considered as system output.

3.2.6. Independent and Exempt Indicators. Independent and exempt indicators around the graph axis in area 1 are identified as independent system indicators. This means that these indicators are not significantly influenced by other system indicators and have little or no effect on them. These indicators have very little to do with the system because they do not stop the main indicator nor evolve a variable in the system.

3.2.7. Discrete Indicators. The position of the power output indicator at peak hours (code 2) indicates that the position of the power output index at peak hours (code 2) has nothing to do with the current dynamics and changes of the system in the application of modern energy in order to sustain the region, and they can be logged out of the system.

3.2.8. Leverage and Secondary Indicators. Leverage and secondary indicators (codes 7, 8, 9, 12, 16, 18, 23, 25, 27, 28, $31,35,36$ and 39) have a strong impact on the system, rather than being effective and have leverage role in its dynamics, and they can be of particular interest as a starting point to start.

3.2.9. Regulatory Indicators. Regulatory indicators (codes 6, $15,17,21$, and 22) can actually act as secondary leverage, weak targets, or secondary risk indicators around the centre of the chart. 
Potential direct influence graph

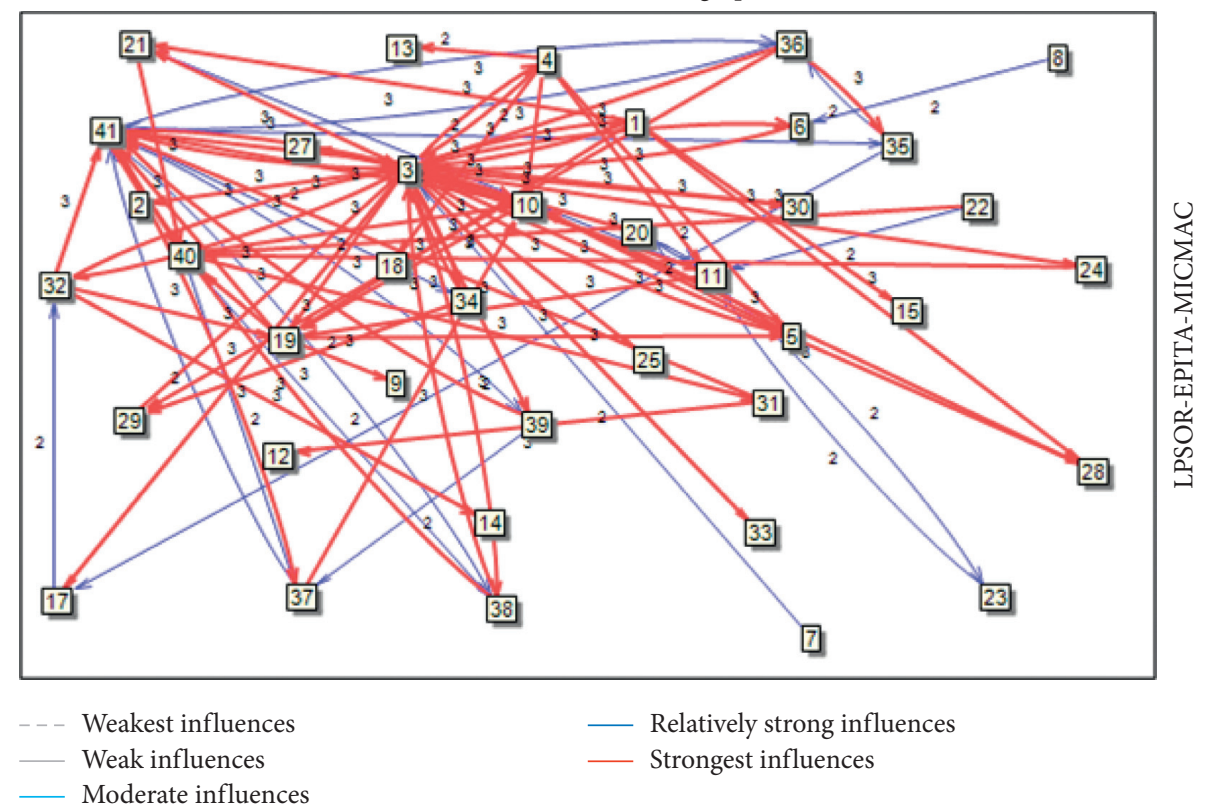

FIGURE 1: Direct effects between indicators and relationships between them (MICMAC software output).

Finally, Figure 2 shows a graphical representation of the indicators studied in relation to new energy utilization pattern in the Tehran area 4 based on the indirect matrix. Indirect effects of indicators on other system indicators are illustrated in this figure. How indicators affect the weakest effects, weak effects, intermediate effects, strong effects, and potential effects is visible.

Figure 3 shows the potential direct and indirect effects of the indicators evaluated. As can be seen, in addition to the relationships between the indices, there are also potential relationships between them that can be used in the final analysis to develop a model for the use of modern energy for sustainable development. As can be seen, the indicators (code 4) (code 3) (code 6) (code 41) (code 19) are assigned. As mentioned, these codes have the highest priority.

\subsection{Identify the Strategic Variables in the Chart. Strategic} variables can be manipulated and affect the dynamics and change of the system. With this description, variables that have a very high impact but cannot be controlled cannot be considered a strategic variable. Assuming the status chart of variables as a coordinate network, the variables in zone 2 have such a situation, and planners can rarely change these variables. As shown in the diagram, variables located in zone 3 of the coordinate network have a very low impact on the system, and they cannot be considered strategic variables. Zone 4 variables also have no strategic relevance due to their strong dependence on other variables, and they are often the result of other variables. However, the coordinate network's zone 1 variables are strategic variables because they are both manageable by the management system and have an acceptable impact on the system. The closer we get from the end of zone 3 to the end of zone 1 of the coordinate network, the greater the variable's importance and strategic importance. Thus, by providing explanations and examining the indicators related to the research's nature, identifying the influential indicators in presenting the proposed model of application of modern energy in District 4 of Tehran is discussed. According to the explanation of Figure 4, in the matrix, the direct effects of indices (codes 3, 5, 11, 19, 32, and 41), are almost the priorities of the direct matrix which are key indicators of the model.

3.4. System Stability and Instability. The distribution of variables within the graph indicates the degree of stability or instability of the system. If the variables are in the form of $L$ in the graph, the system is stable, and this state of the system indicates the stability of the influencing variables and their persistence over the other variables. If the variables are scattered from the coordinate axis to the bottom of the graph, the system is unstable, and the lack of effective variables threatens the system. Figure 5 shows the schematic representation of stable and unstable systems.

As can be seen, Figure 6 illustrates the unstable situation of District 4 of Tehran in the current situation for the use of new energy at the urban level. In order to improve the status situation, considering the results of this study and the software outputs and taking into account the factors driving and prioritizing them, a sustainable model can be put in place to change the situation in favour of the use of new energy at the regional level. 
Potential indirect influence graph

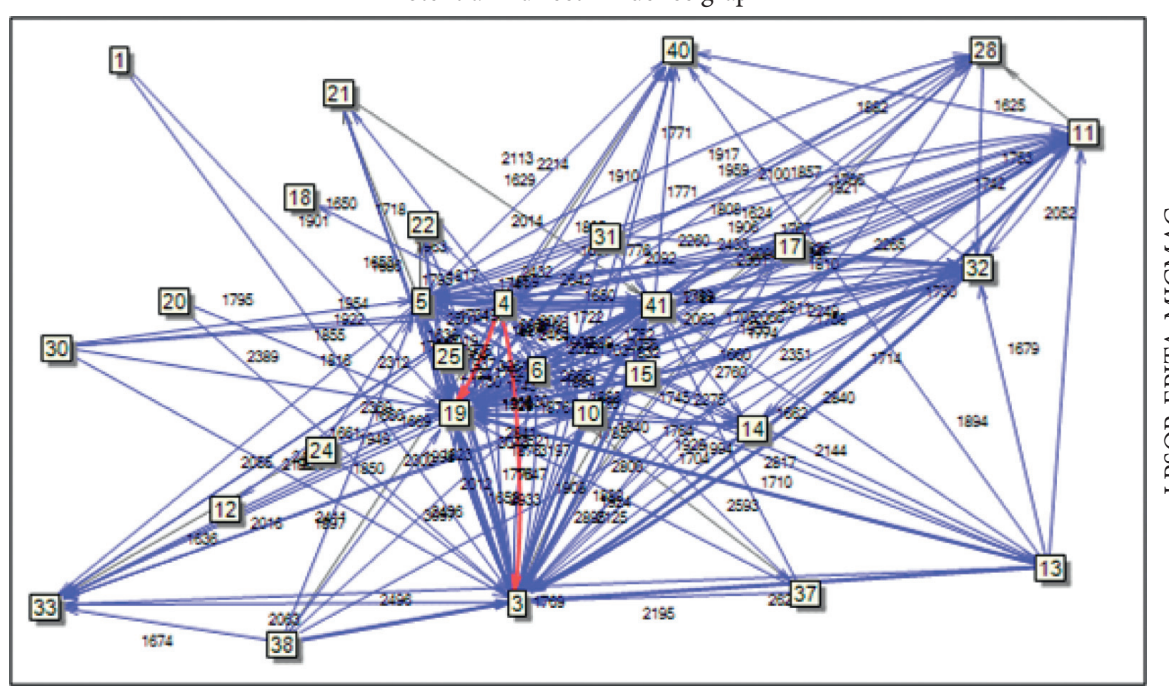

它

- - Weakest influences

- Relatively strong influences

Weak influences

_ Strongest influences

__ Moderate influences

FIGURE 2: Indirect effects between indicators and their interactions (MICMAC software output).

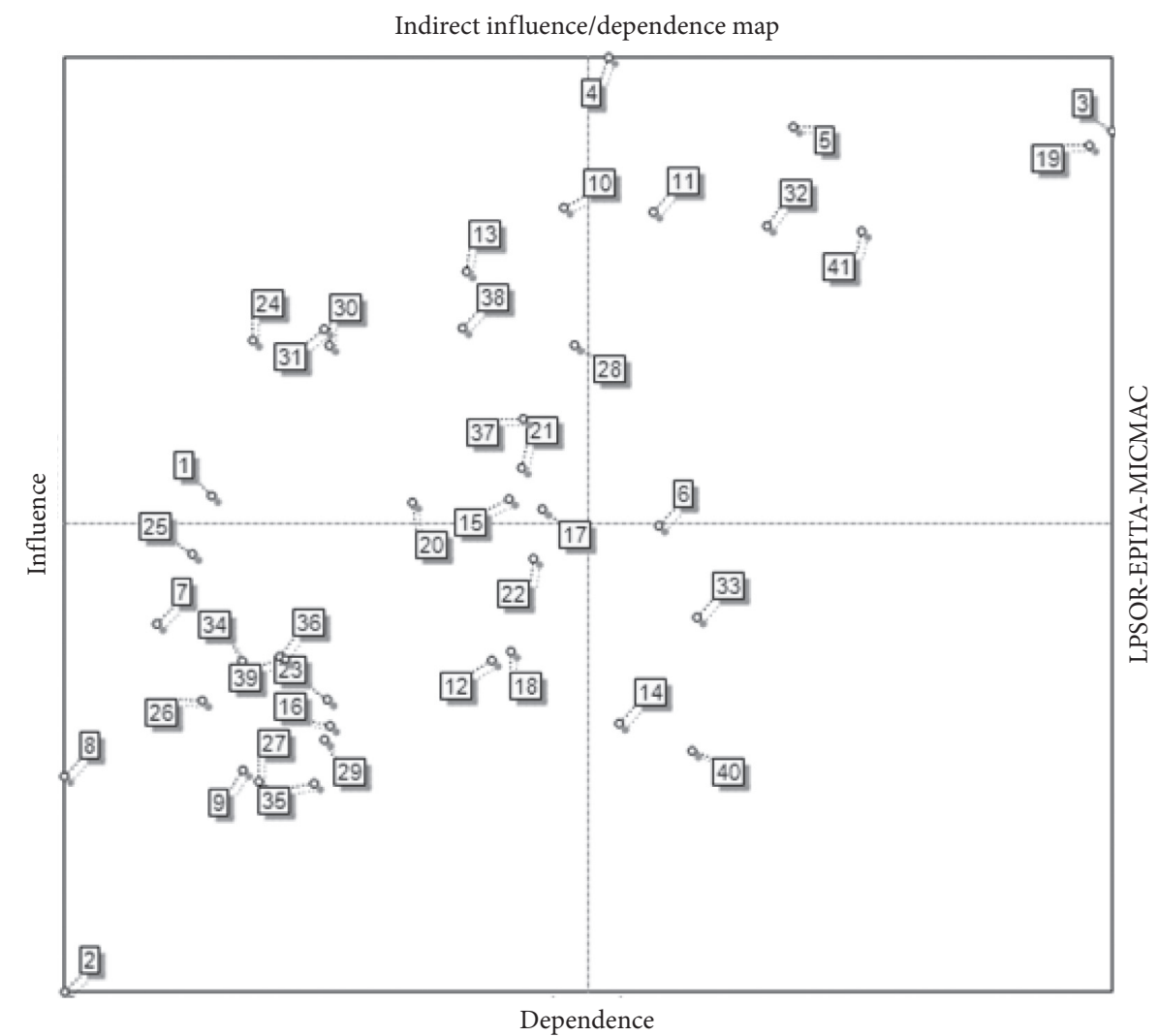

FIGURE 3: Distribution of indicators and their position in the influence-impact matrix of potential impacts (MICMAC software output). 


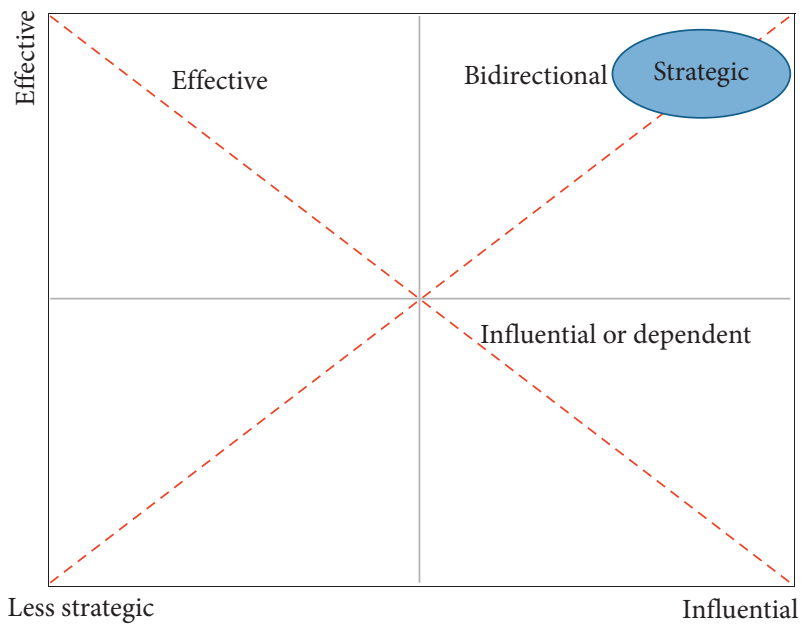

FIgURE 4: Positioning of strategic variables in graphs [51].

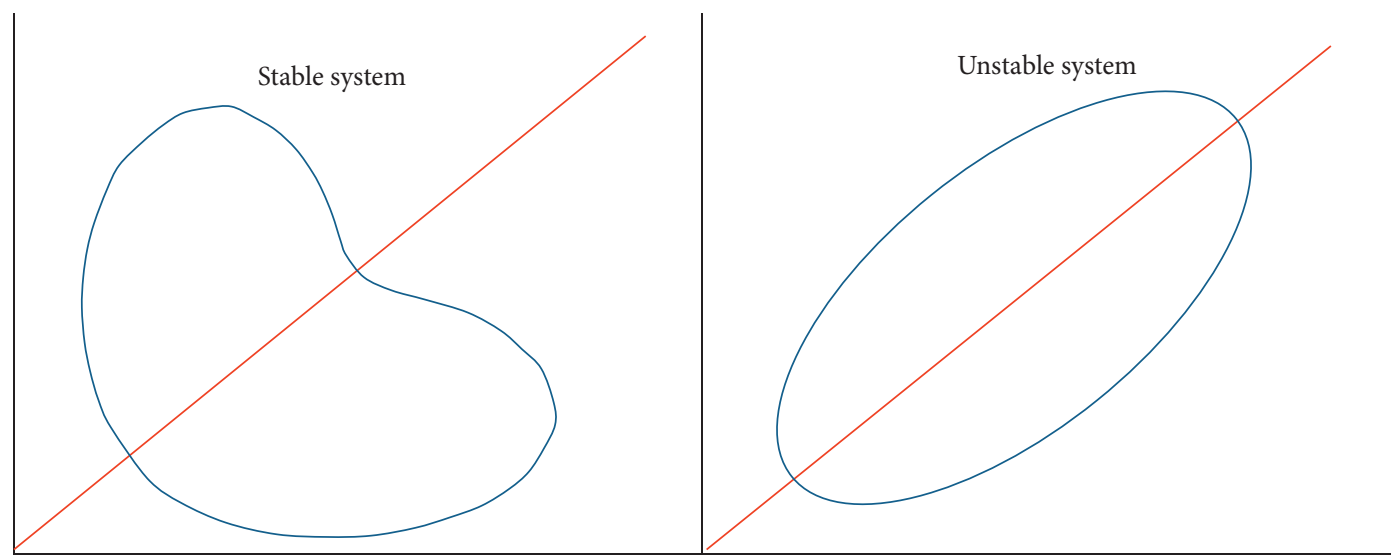

FIgURE 5: Schematic representation of stable and unstable systems [52].

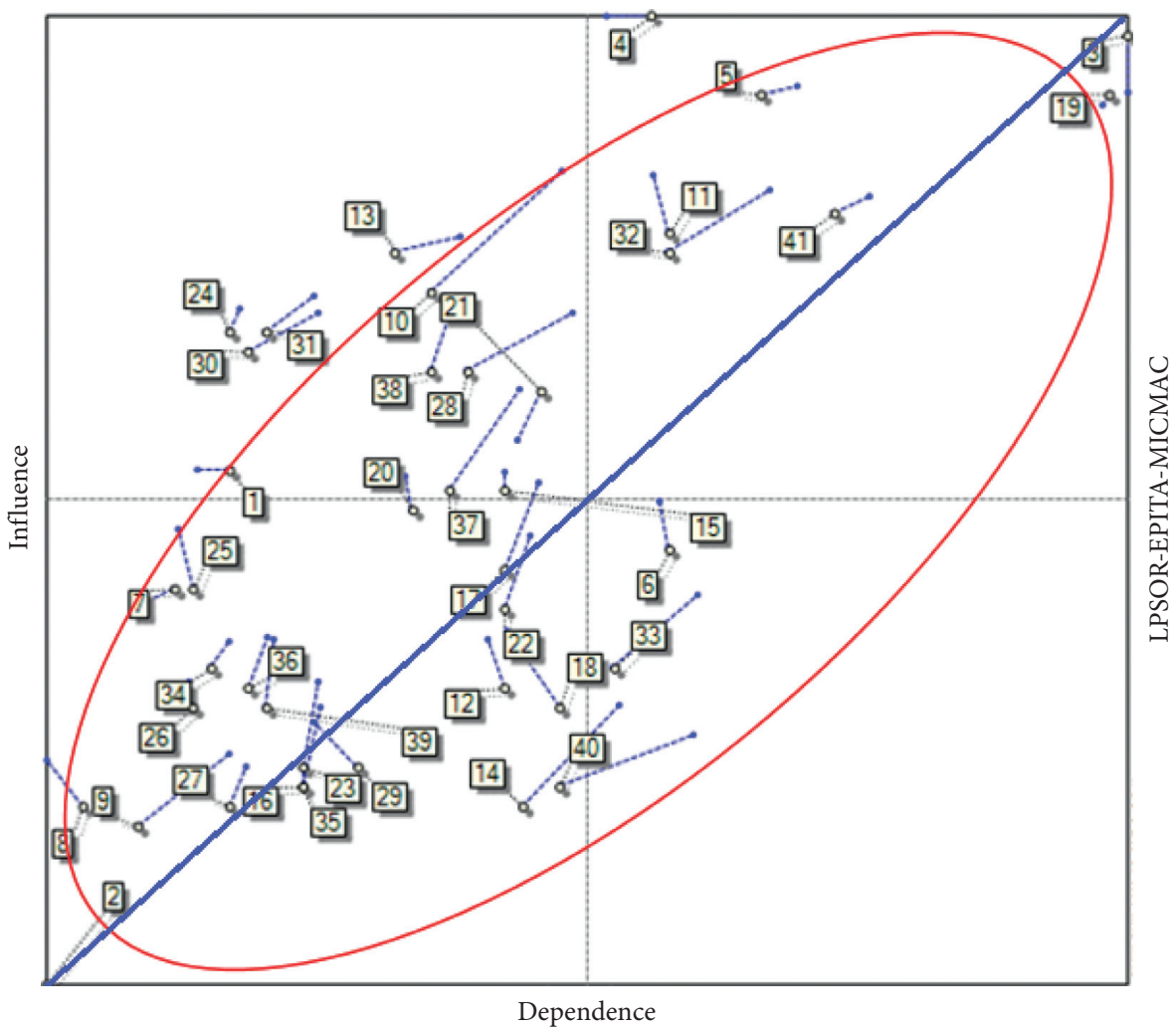

FIgURE 6: Stability of the system under study (MICMAC software output). 


\section{Conclusion}

Patterns have so far been proposed for modern energy use at different levels, based on existing approaches. In this study, MICMAC software was used to provide a model for applying renewable energies in District 4 of Tehran to provide a precise model based on sound strategies. The general and significant results of this model show that the development of renewable energies is not a path that an organ or government can implement alone, and it requires the involvement of the whole community. Here are two types of short-term planning in which more emphasis is placed on competitiveness in the use of renewable energy technologies and the development of the market for distributed electricity generation from renewable energies. Also, in long-term planning, renewable energy finds its main path and will be completely integrated into the national energy planning process. Renewable energy producers will increasingly be competing with other alternative energy sources based on the cost of the product. Based on the research results, generally, the pattern of utilization and development of renewable energies can be classified into five main groups: financial instruments utilization, use of legal tools, technology development, education and awareness-raising.

The use of appropriate financial instruments provides an appropriate level of investment in newer technologies to develop renewable and sustainable energy programs, which will be compared with the potential of national renewable resources. In this regard, together with international resources, public resources will be guided appropriately in meeting these objectives. Furthermore, the right investment space will attract foreign and local investors. International financial institutions can guarantee the creation of new power plants and facilities around the world by providing resources and credits. These institutions play an important role in determining the future composition of energy sources through direct lending, credit guarantees, or policy guidance.

The purpose of applying legal instruments is to develop, implement, and maintain an effective legal system to develop renewable energy, which has been emphasized in this study. In this regard, an appropriate legal framework for pricing and tariff structure should be designed to support the renewable energy coalition in the energy economy and to attract investors. Furthermore, this legal framework should be able to encourage independent power producers and local producers of liquid and gas fuels to use renewable resources in their systems. In Iran, parliament as the legislator's reference in the creation of national laws related to renewable energies and in the energy, debate at national and international level plays a fundamental role that the most important of these are as follows:

(i) Adopting laws to increase the share of renewable energy in the country's energy basket

(ii) Ensuring that new government commitments to increase the share of renewable energy are announced

(iii) Eliminating fossil fuel subsidies (iv) Trying to reform the tax system

(v) Moreover, promoting energy efficiency programs

The development of sustainable renewable energy technologies with appropriate standards is another important strategy in developing renewable energy use. In this regard, local research and development and production should be encouraged to promote renewable energy technology's optimal use. Also, the application of machine learning, such as models in [53-55], and neural network models such as models in [56-61] is welcomed to detect the relation among the crucial components for developing renewable energy.

Public awareness, empowerment, and education strategy require the use of mechanisms to raise public awareness of the benefits and opportunities of renewable energy to increase its use and develop its market by disseminating information on the economic, environmental, social, and commercial benefits of renewable energy technologies. The government and related government institutions should be encouraged to promote educational programs in this field. Communication between national, provincial, and local government agencies on renewable energy policies can play a decisive role in this relationship. Meantime, the mass media determine the quality of information presentation and dissemination. In this regard, the mass media in the field of renewable energies perform the following tasks: taking into account the social and environmental aspects of reporting, introducing the benefits of renewable energies and environmental damage and human health from fossil fuels, news coverage of renewable energies and its introduction as an appropriate solution to the climate change problem, and an effective factor in sustainable development.

There are several future directions that we recommend for other researchers. The optimization approaches such as methods in [62-70] can be applied to address the efficacy and detecting the most effective sustainable development factors for a case study. Also, feature selection methods are required as a preprocessing step [71-78] for detecting the most effective and sustainable development factors. Another direction that we will investigate is an exploratory analysis using optimized prediction tasks as developed in [79-83] and optimization algorithms as proposed in [84-88].

\section{Data Availability}

The data used to support the findings of this study are available from the corresponding author upon request.

\section{Conflicts of Interest}

The authors declare that they have no conflicts of interest.

\section{Acknowledgments}

This study did not take any specific grant from funding organisations in the public, commercial, or not-for-profit sectors. 


\section{References}

[1] J. Yan, W. Pu, S. Zhou, H. Liu, and M. S. Greco, "Optimal resource allocation for asynchronous multiple targets tracking in heterogeneous radar networks," IEEE Transactions on Signal Processing, vol. 68, pp. 4055-4068, 2020.

[2] A. A. S. A. Ghareh Gozloo, "A major conceptual analysis of traffic pollution control in urban management in order to provide a framework consistent with the sustainability paradigm in financing municipalities," Geography and Urban Planning of the Zagros Vision Quarterly, vol. 9, 2013.

[3] J.-W. Hu, "A survey on multi-sensor fusion based obstacle detection for intelligent ground vehicles in off-road environments," Frontiers of Information Technology \& Electronic Engineering, vol. 21, no. 5, pp. 675-692, 2020.

[4] H. Zheng, C. Zhang, and M. Shadabfar, "Beam damage detection under a moving load using random decrement technique and Savitzky-Golay filter," Sensors, vol. 20, no. 1, p. $243,2020$.

[5] H. Kordestani and C. Zhang, "Direct use of the savitzky-golay filter to develop an output-only trend line-based damage detection method," Sensors, vol. 20, no. 7, p. 1983, 2020.

[6] A. A. Mousavi, C. Zhang, S. F. Masri, and G. Gholipour, "Structural damage localization and quantification based on a ceemdan hilbert transform neural network approach: a model steel truss bridge case study," Sensors, vol. 20, no. 5, p. 1271, 2020.

[7] C. Li, L. Sun, Z. Xu, X. Wu, T. Liang, and W. Shi, "Experimental investigation and error analysis of high precision FBG displacement sensor for structural health monitoring," International Journal of Structural Stability and Dynamics, vol. 20, no. 6, Article ID 2040011, 2020.

[8] L. Sun, C. Li, C. Zhang, T. Liang, and Z. Zhao, "The strain transfer mechanism of fiber bragg grating sensor for extra large strain monitoring," Sensors, vol. 19, no. 8, p. 1851, 2019.

[9] C. Zhang, Z. Alam, L. Sun, Z. Su, and B. Samali, "Fibre bragg grating sensor-based damage response monitoring of an asymmetric reinforced concrete shear wall structure subjected to progressive seismic loads," Structural Control and Health Monitoring, vol. 26, no. 3, Article ID e2307, 2019.

[10] L. Sun, C. Li, C. Zhang, Z. Su, and C. Chen, "Early monitoring of rebar corrosion evolution based on FBG sensor," International Journal of Structural Stability and Dynamics, vol. 18, no. 8, Article ID 1840001, 2018.

[11] C. Cai, X. Wu, W. Liu et al., "Selective laser melting of near- $\alpha$ titanium alloy Ti-6Al-2Zr-1Mo-1V: parameter optimization, heat treatment and mechanical performance," Journal of Materials Science \& Technology, vol. 57, pp. 51-64, 2020.

[12] C. Cai, X. Gao, Q. Teng et al., "Hot isostatic pressing of a near $\alpha$-Ti alloy: temperature optimization, microstructural evolution and mechanical performance evaluation," Materials Science and Engineering: A, vol. 802, Article ID 140426, 2020.

[13] X. Wang, Y. Liu, and K.-K. R. Choo, "Fault tolerant multisubset aggregation scheme for smart grid," IEEE Transactions on Industrial Informatics, vol. 848, p. 1, 2020.

[14] S. Xu, J. Wang, W. Shou, T. Ngo, A.-M. Sadick, and X. Wang, "Computer vision techniques in construction: a critical review," Archives of Computational Methods in Engineering, 2020.

[15] J. Yan, W. Pu, S. Zhou, H. Liu, and Z. Bao, "Collaborative detection and power allocation framework for target tracking in multiple radar system," Information Fusion, vol. 55, pp. 173-183, 2020.
[16] Q. Zhu, "Research on road traffic situation awareness system based on image big data," IEEE Intelligent Systems, vol. 35, no. 1, pp. 18-26, 2019.

[17] Q. Jiang, F. Shao, W. Gao, Z. Chen, G. Jiang, and Y.-S. Ho, "Unified no-reference quality assessment of singly and multiply distorted stereoscopic images," IEEE Transactions on Image Processing, vol. 28, no. 4, pp. 1866-1881, 2018.

[18] M. Xu, C. Li, S. Zhang, and P. L. Callet, "State-of-the-art in $360^{\circ}$ video/image processing: perception, assessment and compression," IEEE Journal of Selected Topics in Signal Processing, vol. 14, no. 1, pp. 5-26, 2020.

[19] M. Yang and A. Sowmya, "An underwater color image quality evaluation metric," IEEE Transactions on Image Processing, vol. 24, no. 12, pp. 6062-6071, 2015.

[20] B. Wang, B. Zhang, and X. Liu, "An image encryption approach on the basis of a time delay chaotic system," Optik-International Journal for Light and Electron Optics, vol. 225, Article ID 165737, 2020.

[21] S. Hinojosa, D. Oliva, E. Cuevas, G. Pajares, D. Zaldivar, and M. Pérez-Cisneros, "Reducing overlapped pixels: a multiobjective color thresholding approach," Soft Computing, vol. 24, no. 9, pp. 6787-6807, 2020.

[22] C. Wu, P. Wu, J. Wang, R. Jiang, M. Chen, and X. Wang, "Critical review of data-driven decision-making in bridge operation and maintenance," Structure and Infrastructure Engineering, pp. 1-24, 2020.

[23] S. Liu, W. Yu, F. T. S. Chan, and B. Niu, "A variable weightbased hybrid approach for multi-attribute group decision making under interval-valued intuitionistic fuzzy sets," International Journal of Intelligent Systems, vol. 36, no. 2, 2020.

[24] S. Liu, F. T. S. Chan, and W. Ran, "Decision making for the selection of cloud vendor: an improved approach under group decision-making with integrated weights and objective/subjective attributes," Expert Systems with Applications, vol. 55, pp. 37-47, 2016.

[25] A. R. A. M. M. K. G. Kazemian, "The place of renewable and renewable energies in the biodiversity of cities case study of Tehran," Journal of Urban Research and Planning, vol. 8, no. 22, pp. 99-188, 2016.

[26] M. Bottero, C. D’Alpaos, and A. Oppio, "Decision-making for urban planning and regional development," Advances in Operations Research, vol. 2019, Article ID 5178051, 2 pages, 2019.

[27] Z. Lukszo, E. Bompard, P. Hines, and L. Varga, "Energy and complexity," Complexity, vol. 2018, Article ID 6937505, 2 pages, 2018.

[28] J. A. León, G. Montero, M. A. Coronado et al., "Renewable energy integration: economic assessment of solar energy to produce biodiesel at supercritical conditions," International Journal of Photoenergy, vol. 2018, Article ID 8769582, 9 pages, 2018.

[29] Y. Shen, R. Wei, and L. Xu, "Energy consumption prediction of a greenhouse and optimization of daily average temperature," Energies, vol. 11, no. 1, p. 65, 2018.

[30] A.-J. Perea-Moreno, M.-Á. Perea-Moreno, Q. HernandezEscobedo, and F. Manzano-Agugliaro, "Towards forest sustainability in Mediterranean countries using biomass as fuel for heating," Journal of Cleaner Production, vol. 156, pp. 624-634, 2017.

[31] A.-J. Perea-Moreno, M.-J. Aguilera-Ureña, and F. ManzanoAgugliaro, "Fuel properties of avocado stone," Fuel, vol. 186, pp. 358-364, 2016.

[32] M. J. Sorgato, K. Schneider, and R. Rüther, "Technical and economic evaluation of thin-film CdTe building-integrated 
photovoltaics (BIPV) replacing façade and rooftop materials in office buildings in a warm and sunny climate," Renewable Energy, vol. 118, pp. 84-98, 2018.

[33] D. La Cruz-Lovera, A.-J. Perea-Moreno, D. La CruzFernández, J. A. Alvarez-Bermejo, and F. Manzano-Agugliaro, "Worldwide research on energy efficiency and sustainability in public buildings," Sustainability, vol. 9, no. 8, p. 1294, 2017.

[34] B. Marchi and S. Zanoni, "Supply chain management for improved energy efficiency: review and opportunities," Energies, vol. 10, no. 10, p. 1618, 2017.

[35] L. Zhao and Z. Zhou, "Developing a rating system for building energy efficiency based on in situ measurement in China," Sustainability, vol. 9, no. 2, p. 208, 2017.

[36] J. Aggarwal and M. L. Aggarwal, "Harnessing solar energy for every home: energy saving applications," Conference Papers in Science, vol. 2014, Article ID 628294, 3 pages, 2014.

[37] M. Soltani, O. Rahmani, A. Beiranvand Pour, Y. Ghaderpour, I. Ngah, and S. H. Misnan, "Determinants of variation in household energy choice and consumption: case from Mahabad city, Iran," Sustainability, vol. 11, no. 17, p. 4775, 2019.

[38] O. Rahmani, S. Rezania, A. Beiranvand Pour et al., "An overview of household energy consumption and carbon dioxide emissions in Iran," Processes, vol. 8, no. 8, p. 994, 2020.

[39] L. D. D. Harvey, "Resource implications of alternative strategies for achieving zero greenhouse gas emissions from light-duty vehicles by 2060," Applied Energy, vol. 212, pp. 663-679, 2018.

[40] A.-J. Perea-Moreno and Q. Hernandez-Escobedo, "Solar resource for urban communities in the Baja California Peninsula, Mexico,” Energies, vol. 9, no. 11, p. 911, 2016.

[41] C. Filippín, S. Flores Larsen, and F. Ricard, "Improvement of energy performance metrics for the retrofit of the built environment. Adaptation to climate change and mitigation of energy poverty," Energy and Buildings, vol. 165, pp. 399-415, 2018.

[42] H. M. Munir, R. Ghannam, H. Li et al., "Control of distributed generators and direct harmonic voltage controlled active power filters for accurate current sharing and power quality improvement in islanded microgrids," Inventions, vol. 4, no. 2, p. 27, 2019.

[43] Z. Xu, Y. Gao, M. Hussain, and P. Cheng, "Demand side management for smart grid based on smart home appliances with renewable energy sources and an energy storage system," Mathematical Problems in Engineering, vol. 2020, Article ID 9545439, 20 pages, 2020.

[44] S. K. Murthy, A. Goyal, N. Rajasekar, K. Pareek, T. T. Nguyen, and A. Garg, "Predictive modelling and surface analysis for optimization of production of biofuel as A renewable energy resource: proposition of artificial neural network search," Mathematical Problems in Engineering, vol. 2020, Article ID 4065964, 13 pages, 2020.

[45] A. Sadeghpour and G. Ozay, "Evaluation of reinforced concrete frames designed based on previous Iranian seismic codes," Arabian Journal for Science and Engineering, vol. 45, no. 10, pp. 8069-8085, 2020.

[46] A. Addeh, A. Khormali, and N. A. Golilarz, "Control chart pattern recognition using RBF neural network with new training algorithm and practical features," ISA Transactions, vol. 79, pp. 202-216, 2018.

[47] A. Curreli, G. Serra-Coch, A. Isalgue, I. Crespo, and H. Coch, "Solar energy as a form giver for future cities," Energies, vol. 9, no. 7, p. 544, 2016.
[48] E. Laiola and P. Giungato, "Wind characterization in Taranto city as a basis for innovative sustainable urban development," Journal of Cleaner Production, vol. 172, pp. 3535-3545, 2018.

[49] J. Z. Thellufsen and H. Lund, "Roles of local and national energy systems in the integration of renewable energy," Applied Energy, vol. 183, pp. 419-429, 2016.

[50] Tehran center for studies and planning, "Detailed Plan of Tehran District 4." Municipality of Tehran, 2006.

[51] N. Zali, T. Rabbani, and V. V. Motti, "Application of prospective structural analysis for identification of strategic variables in the future development of Baneh City in Iran," European Spatial Research and Policy, vol. 22, no. 1, pp. 153-171, 2015.

[52] J. Arcade, M. Godet, F. Meunier, and F. Roubelat, "Structural analysis with the MICMAC method \& actor's strategy with MACTOR method," Futures Research Methodology, vol. 3, 1999.

[53] X. Zhang, T. Wang, W. Luo, and P. Huang, "Multi-level fusion and attention-guided CNN for image dehazing," IEEE Transactions on Circuits and Systems for Video Technology, p. $1,2020$.

[54] X. Zhang, D. Wang, Z. Zhou, and Y. Ma, "Robust low-rank tensor recovery with rectification and alignment," IEEE Transactions on Pattern Analysis and Machine Intelligence, vol. 43, no. 1, pp. 238-255, 2019.

[55] X. Zhang, R. Jiang, T. Wang, and J. Wang, "Recursive neural network for video deblurring," IEEE Transactions on Circuits and Systems for Video Technology, vol. 8, p. 1, 2020.

[56] D. Zhao, L. Liua, F. Yua et al., "Chaotic random spare ant colony optimization for multi-threshold image segmentation of 2D Kapur entropy," Knowledge-Based Systems, vol. 216, Article ID 106510, 2020.

[57] H.-L. Chen, G. Wang, C. Ma, Z.-N. Cai, W.-B. Liu, and S.-J. Wang, "An efficient hybrid kernel extreme learning machine approach for early diagnosis of Parkinson's disease," Neurocomputing, vol. 184, pp. 131-144, 2016.

[58] L. Hu, G. Hong, J. Ma, X. Wang, and H. Chen, “An efficient machine learning approach for diagnosis of paraquat-poisoned patients," Computers in Biology and Medicine, vol. 59, pp. 116-124, 2015.

[59] J. Xia, H. Chen, Q. Li et al., "Ultrasound-based differentiation of malignant and benign thyroid Nodules: an extreme learning machine approach," Computer Methods and Programs in Biomedicine, vol. 147, pp. 37-49, 2017.

[60] C. Li, L. Hou, B. Y. Sharma et al., "Developing a new intelligent system for the diagnosis of tuberculous pleural effusion," Computer Methods and Programs in Biomedicine, vol. 153, pp. 211-225, 2018.

[61] X. Xu and H.-L. Chen, "Adaptive computational chemotaxis based on field in bacterial foraging optimization," Soft Computing, vol. 18, no. 4, pp. 797-807, 2014.

[62] H. Yu, W. Li, C. Cheng et al., "Dynamic Gaussian bare-bones fruit fly optimizers with abandonment mechanism: method and analysis," Engineering with Computers, pp. 1-29, 2020.

[63] J. Hu, H. Chen, A. A. Heidari et al., "Orthogonal learning covariance matrix for defects of grey wolf optimizer: insights, balance, diversity, and feature selection," Knowledge-Based Systems, vol. 213, Article ID 106684, 2021.

[64] C. Yu, M. Chen, K. Cheng et al., "SGOA: annealing-behaved grasshopper optimizer for global tasks," Engineering with Computers, pp. 1-28, 2021.

[65] W. Shan, Z. Qiao, A. A. Heidari, H. Chen, H. Turabieh, and Y. Teng, "Double adaptive weights for stabilization of moth flame optimizer: balance analysis, engineering cases, and 
medical diagnosis," Knowledge-Based Systems, vol. 214, Article ID 106728, 2020.

[66] J. Tu, H. Chen, J. Liu et al., "Evolutionary biogeography-based whale optimization methods with communication structure: towards measuring the balance," Knowledge-Based Systems, vol. 212, Article ID 106642, 2021.

[67] H. Chen, A. A. Heidari, H. Chen, M. Wang, Z. Pan, and A. H. Gandomi, "Multi-population differential evolutionassisted Harris hawks optimization: framework and case studies," Future Generation Computer Systems, vol. 111, pp. 175-198, 2020.

[68] X. Zhao, X. Zhang, Z. Cai et al., "Chaos enhanced grey wolf optimization wrapped ELM for diagnosis of paraquat-poisoned patients," Computational Biology and Chemistry, vol. 78, pp. 481-490, 2019.

[69] Y. Xu, H. Chen, J. Luo, Q. Zhang, S. Jiao, and X. Zhang, "Enhanced Moth-flame optimizer with mutation strategy for global optimization," Information Sciences, vol. 492, pp. 181203, 2019.

[70] M. Wang and H. Chen, "Chaotic multi-swarm whale optimizer boosted support vector machine for medical diagnosis," Applied Soft Computing Journal, vol. 88, Article ID 105946, 2020.

[71] X. Zhao, D. Li, B. Yang, C. Ma, Y. Zhu, and H. Chen, "Feature selection based on improved ant colony optimization for online detection of foreign fiber in cotton," Applied Soft Computing, vol. 24, pp. 585-596, 2014.

[72] Y. Zhang, R. Liu, A. A. Heidari et al., "Towards augmented kernel extreme learning models for bankruptcy prediction: algorithmic behavior and comprehensive analysis," Neurocomputing, vol. 430, 2020.

[73] Y. Zhang, R. Liu, X. Wang, H. Chen, and C. Li, "Boosted binary Harris hawks optimizer and feature selection," Engineering with Computers, pp. 1-30, 2020.

[74] L. Shen, H. Chen, Z. Yu et al., "Evolving support vector machines using fruit fly optimization for medical data classification," Knowledge-Based Systems, vol. 96, pp. 61-75, 2016.

[75] M. Wang, H. Chen, B. Yang et al., "Toward an optimal kernel extreme learning machine using a chaotic moth-flame optimization strategy with applications in medical diagnoses," Neurocomputing, vol. 267, pp. 69-84, 2017.

[76] X. Zhang, J. Wang, T. Wang, R. Jiang, J. Xu, and L. Zhao, "Robust feature learning for adversarial defense via hierarchical feature alignment," Information Sciences, vol. 560, 2020.

[77] X. Zhang, M. Fan, D. Wang, P. Zhou, and D. Tao, “Top-k feature selection framework using robust 0-1 integer programming," IEEE Transactions on Neural Networks and Learning Systems, pp. 1-15, 2020.

[78] X. Zhang, T. Wang, J. Wang, G. Tang, and L. Zhao, "Pyramid channel-based feature attention network for image dehazing," Computer Vision and Image Understanding, vol. 197198 pages, 2020.

[79] W. Zhu, C. Ma, X. Zhao et al., "Evaluation of sino foreign cooperative education project using orthogonal sine cosine optimized kernel extreme learning machine," IEEE Access, vol. 8, pp. 61107-61123, 2020.

[80] G. Liu, W. Jia, M. Wang et al., "Predicting cervical hyperextension injury: a covariance guided sine cosine support vector machine," IEEE Access, vol. 8, pp. 46895-46908, 2020.

[81] Y. Wei, H. Lv, M. Chen et al., "Predicting entrepreneurial intention of students: an extreme learning machine with Gaussian barebone harris hawks optimizer," IEEE Access, vol. 8, pp. 76841-76855, 2020.
[82] H. Tang, Y. Xu, A. Lin et al., "Predicting green consumption behaviors of students using efficient firefly grey wolf-assisted K-nearest neighbor classifiers," IEEE Access, vol. 8, pp. 35546-35562, 2020.

[83] A. Lin, Q. Wu, A. A. Heidari et al., "Predicting intentions of students for master programs using a chaos-induced sine cosine-based fuzzy K-nearest neighbor classifier," IEEE Access, vol. 7, pp. 67235-67248, 2019.

[84] Y. Fan, P. Wang, A. A. Heidari et al., "Rationalized fruit fly optimization with sine cosine algorithm: a comprehensive analysis," Expert Systems with Applications, vol. 157, Article ID 113486, 2020.

[85] E. Rodríguez-Esparza, L. A. Zanella-Calzada, D. Oliva et al., "An efficient Harris hawks-inspired image segmentation method," Expert Systems with Applications, vol. 155, Article ID 113428, 2020.

[86] S. Jiao, G. Chong, C. Huang et al., "Orthogonally adapted Harris hawks optimization for parameter estimation of photovoltaic models," Energy, vol. 203, Article ID 117804, 2020.

[87] Z. Xu, Z. Hu, A. A. Heidari et al., "Orthogonally-designed adapted grasshopper optimization: a comprehensive analysis," Expert Systems with Applications, vol. 150, Article ID $113282,2020$.

[88] A. Abbassi, R. Abbassi, A. A. Heidari et al., "Parameters identification of photovoltaic cell models using enhanced exploratory salp chains-based approach," Energy, vol. 198, Article ID 117333, 2020. 